\title{
SABERES EM VIAGEM NOS MANUAIS PEDAGÓGICOS (PORTUGAL - BRASIL)
}

\author{
VIVIAN BATISTA DA SILVA \\ Faculdade de Educação da Universidade de São Paulo \\ eddiebs@terra.com.br \\ ANTÓNIO CARLOS DA LUZ CORREIA
}

Faculdade de Psicologia e Ciências da Educação da Universidade de Lisboa

antonio_carloscorreia@hotmail.com

\begin{abstract}
RESUMO
Este trabalho procura sistematizar e aprofundar a problematização acerca do lugar ocupado pelos manuais de Pedagogia, Didática, Metodologia e Prática de Ensino utilizados em cursos de formação de professores, na produção e circulação intra e internacional do discurso pedagógico e profissional docente. A reflexão dá continuidade a estudos anteriores já realizados pelos autores numa perspectiva socioistórica comparada, no âmbito de um projeto maior sob o título: Estudos comparados sobre a escola: Brasil e Portugal (séculos XIX e XX), financiado na parte brasileira pelo Acordo Capes-ICCTI. Tal colaboração insere-se também no âmbito do Prestige, programa financiado pela União Européia. O artigo tece considerações sobre levantamento razoavelmente extenso da literatura produzida sobre manuais escolares e para professores, analisando a predominância de certos tópicos e de diretrizes específicas de pesquisas na área. Esses elementos ajudam a entender como as produções sobre o objeto de estudo foram geradas e postas em circulação, colaborando para a construção da história da história dos manuais pedagógicos e do discurso educacional.

FORMAÇÃO DEPROFESSORES - MANUAL - HISTÓRIA DA EDUCAÇÃO-PORTUGAL BRASIL
\end{abstract}

Este texto foi originalmente apresentado no $25^{\circ}$ International Standing Conference for the History of Education - ISCHE - (São Paulo, jul. 2003) e resulta de pesquisa que conta com bolsa de doutorado da Fundação de Amparo à Pesquisa do Estado de São Paulo - Fapesp - e bolsa de doutorado sanduíche da Coordenação de Aperfeiçoamento do Pessoal de Nível Superior Capes. 


\section{ABSTRACT}

KNOWEDGEINAJOURNEYTHROUGHPEDAGOG/CAL MANUALS(PORTUGAL-BRAZIL). This paper intends to systematize and deepen the questioning regarding the space of Education Pedagogical, Didactic, Methodological, and Practical manuals, used in courses for future teachers, in the national and international production and circulation of pedagogical and professional discourse. The reflection continues previous studies by the authors from a comparative sociohistorical perspective, within a more far-reaching project entitled: Comparative study on school: Brazil and Portugal (Nineteenth and twentieth centuries), financed on the Brazilian side by the agreement Capes-ICCTI. This collaboration is also within the scope of Prestige, a program financed by the European Union. The article presents a reasonably extensive study on the literature produced on school manuals for teachers, analyzing the predominance of certain topics and specific research guidelines in the area. These elements help understand how productions on the object of study have been generated and circulated, collaborating to build the history of the history of pedagogical manuals and of the educational discourse.

TEACHEREDUCATION-MANUAL - HISTORY OFEDUCATION_PORTUGAL-BRAZIL

Este trabalho procura sistematizar e aprofundar a problematização sobre o lugar ocupado pelos manuais de Pedagogia, Didática, Metodologia e Prática de Ensino na produção e circulação intra e internacional do discurso pedagógico e profissional docente. A busca de uma reflexão teórica e conceitual mais elaborada acerca desses livros conduz à análise do conhecimento produzido a respeito dos manuais para professores como objeto histórico. Em outras palavras, o nosso esforço é conhecer trabalhos já desenvolvidos acerca desses textos, identificando as questões e os referenciais teórico-conceituais que têm mobilizado os estudos. Temos como preocupação principal discutir e afinar o entendimento dos manuais que se dirigem especificamente à formação para o magistério, diferenciando-os, em sua natureza e forma, dos manuais escolares ou didáticos dirigidos aos alunos do ensino primário. Isso porque, embora tanto os manuais pedagógicos quanto os manuais destinados às crianças destinem-se ao uso escolar, importa notar as especificidades dos livros escritos para os professores, uma vez que guardam uma lógica particular de produção. $\bigcirc$ que procuraremos evidenciar ao longo deste trabalho é que esses manuais são um lugar de construção e circulação de saberes profissionalizantes que, curiosamente, ainda não se afirmam no conjunto das pesquisas sobre o corpo docente e sua formação como um objeto histórico legitimado. Os manuais pedagógicos são assim fonte e objeto ricos para a história da profissiona- 
lização docente no âmbito das escolas normais, uma amostra de como se constitui o saber específico da área, selecionando o que há de "essencial" em termos de conhecimento profissional e consagrando representações acerca do trabalho de ensinar, ou seja, dos modos pelos quais esse trabalho foi tratado e idealizado (Chartier, 1990).

processo de produção desses livros é complexo e envolve diversos fatores, tais como os dispositivos de organização dos conteúdos a serem estudados, constantes dos currículos e programas da escola normal, as leis mediante as quais o governo ordena e controla a literatura escolar em geral e o desenvolvimento de iniciativas editoriais. Esses textos, para além de servirem aos propósitos imediatos de formarem professores, também têm um papel decisivo na configuração do discurso pedagógico, da concepção profissional do professor e dos saberes que a sustentam. A abordagem do modo pelo qual o texto se constrói na interação com outros autores, livros, modelos, países e instituições mostra que ele não se limita a constituir mero artefato ilustrativo do quotidiano na formação dos professores. Isso significa que os manuais pedagógicos, tal como os entendemos, participam da produção histórica dos professores. Seus textos não são apenas proposições, horizontes a serem alcançados, mas, antes, correspondem a discursos que dão a conhecer modos pelos quais, em diferentes tempos e espaços, as atitudes e visões de mundo daqueles que exercem o magistério têm sido estruturados.

A nós interessa saber como os manuais fornecem representações do trabalho docente, legitimando certas maneiras de pensar e agir na profissão. Um esforço dessa natureza permite apreender aquilo que Chartier (| 99|) denomina "lutas de representações", pois atenta para as estratégias simbólicas que, mediante os textos, constituem a identidade de um grupo determinado. Nesse espaço de investigação, é possível pensar "a construção das identidades sociais como resultando sempre de uma relação de força entre as representações impostas pelos que detêm o poder de classificar e de nomear e a definição, de aceitação ou de resistência, que cada comunidade produz de si mesma", e, ainda, "o recorte social objetivado como a tradução do crédito conferido à representação que cada grupo [inclusive o dos professores] dá de si mesmo, logo a sua capacidade de fazer reconhecer sua existência a partir de uma demonstração de unidade" (Chartier, 1991, p. 183).

Pierre Bourdieu (1996) faz considerações de natureza semelhante, assinalando que as representações são um caso particular das "lutas entre classi- 
ficações", ou seja, das "lutas pelo monopólio do poder de fazer ver e de fazer crer, de fazer conhecer e de fazer reconhecer, de impor a definição legítima das divisões do mundo social e, por essa via, de fazer e desfazer os grupos" (Bourdieu, 1996, p. 108). As disputas dessa natureza têm como móvel a possibilidade de impor uma visão do mundo social - no caso dos manuais pedagógicos, uma idéia de profissão docente - mediante os "princípios de divisão" que, ao serem apropriados, determinam um modo de entender a identidade e a unidade de um grupo. De fato, a representação é um conceito central neste estudo, pois, para além de imagens mentais, designa todo um conjunto de manifestações sociais destinadas a manipular estas mesmas imagens. As iniciativas dos produtores dos manuais são entendidas como uma forma de poder exercido sobre os leitores dessas obras, na tentativa de impor a eles princípios de visão e de divisão comuns, enfim, como sugere Bourdieu, "uma visão única de sua identidade e uma visão idêntica de sua unidade" (idem, p. I I I).

Numa perspectiva de análise dessa natureza, importa identificar as regras que governam a elaboração e circulação dos manuais pedagógicos. Embora não tenhamos conhecido nenhuma fonte produzida diretamente pelos leitores desses livros - tais como cadernos ou anotações de leituras feitas pelos próprios normalistas - que permitisse saber como os manuais foram efetivamente lidos, o exame dos textos já nos fornece informações efetivamente completas acerca da construção de discursos que constituem maneiras de perceber ou apreciar o magistério. Pela identificação da presença de referências a autores e instituições nos manuais, torna-se possível captar as relações e as modalidades de produção de tal discurso, verificando, entre outros aspectos, como Portugal e Brasil participam intra e internacionalmente da apropriação, reelaboração e circulação dos saberes que sustentam o ofício de ensinar.

Ao procedermos a um exame socioistórico comparado dos manuais pedagógicos, julgamos ser necessário fazer um levantamento razoavelmente extenso da literatura produzida em torno da temática, em que caracterizamos os tópicos predominantes e o quadro conceitual das diretrizes específicas de pesquisa, configuradas nos modos de elaboração desses livros como objeto de estudo. Alguns dos aspectos considerados nessa sistematização são:

I. número de trabalhos acerca de manuais escolares e de manuais pedagógicos, situando o ano e o lugar de produção;

2. períodos estudados pelos trabalhos; 
3. temas examinados;

4. tipologia de problematização e referenciais teórico-conceituais mobilizados.

Dessa forma, organizamos informações para acompanhar a produção dos estudos sobre manuais, no intuito de refletir sobre os interesses que mobilizam tais esforços, ou, como sugere António Nóvoa (1996), compreender as razões que conduzem à profissionalização dessas pesquisas. Nesse sentido, a metáfora dos "saberes em viagem" refere-se à própria história da história dos manuais, aos modos pelos quais vários interesses e análises têm-se configurado nesse campo de conhecimento. Aqui, importa atentar para as condições nas quais tal produção tem sido gerada e posta em circulação, localizando-se o desenvolvimento e a finalidade de certas preocupações, no interior de diversas instituições e grupos diferenciados e a partir de propostas específicas de exame.

No caso, atentamos para trabalhos desenvolvidos no âmbito do Projeto Investigación sobre los Manuales Escolares - Manes -, com sede na Universidad Nacional de Educación a Distancia de Madrid, que conta com a colaboração de diversas instituições de nível universitário da América Latina, bem como de outro projeto vinculado a esse, o Projeto Historia de la enseñanza de la lectura en Argentina - Histelea. O programa Problems of Educational Standardization and Transitions in a Global Environment - Prestige -, no qual nossos esforços se inserem, aparece abrigando o documento de trabalho que divulga resultados de nosso estudo comparado socioistórico dos manuais pedagógicos portugueses e brasileiros. Também foi incluído nesse levantamento o exame de manuais para professores publicados no Brasil e que se articula a um outro projeto, que é justamente um desdobramento do Prestige, mais atento ao mundo lusófono e que associa pesquisadores da Universidade de São Paulo e da Universidade de Lisboa sob o abrigo do convênio Capes-ICCTI. O título do projeto é: Estudos comparados sobre a escola: Brasil e Portugal (séculos XIX e XX).

Além disso, analisamos alguns trabalhos apresentados no Ische 22, cuja temática versa sobre os livros escolares, as teses e dissertações de mestrado defendidas em instituições de ensino superior brasileiras, como a Universidade de São Paulo, a Pontifícia Universidade Católica de São Paulo, a Universidade Estadual de Campinas (Unicamp) e a Universidade Federal do Rio de Janeiro (UFRJ), entre outras, e artigos publicados na coletânea Historia ilustra- 
da del libro escolar en España de la posguerra a la reforma educativa (cf. Benito, 1998), bem como nos seguintes periódicos: Historia de la Educación: Revista Interuniversitária (2000), Paedagogica Historica: International Journal of the History of Education (2002), Sarmiento: anuário galego de Historia da Educación (1997).

Pretendemos dialogar com tais iniciativas, procurando entender como a nossa proposta de trabalho articula-se nesse amplo conjunto e permite localizar nomes já reconhecidos, como os de Alain Chopin, Antonio Viñao e Augustín Escolano, assim como outros autores cujos trabalhos se referem especificamente a manuais para professores, a exemplo de Michèle Roullet, Antonio Pintado, Peter Cunningham, Carmen Castañeda, António Carlos da Luz Correia, Eliane T. Peres, Anthony Potts, Martti T. Kuikka, José María Hernández Díaz, Sylvia B. Schütze, Teresa Rabazas Romero, Kazinierz Puchowski e Vivian Batista da Silva.

Conforme já afirmamos, os manuais pedagógicos participam da elaboração e divulgação do discurso pedagógico, evidenciando práticas específicas de construção e publicação de conhecimentos sobre educação. Trata-se de sínteses de informações contidas numa vasta literatura, produzida por diversos nomes e relacionada a diferentes instituições e áreas. É assim que determinados saberes constituem-se e circulam através dos manuais, elaborados a partir do entendimento seletivo que seus escritores fizeram de algumas idéias, apresentando-as aos normalistas, direcionando as compreensões que esses alunos poderiam ter da bibliografia citada e organizando discursivamente as práticas em razão do léxico e da semântica disponibilizados. Esperamos explicitar os modos pelos quais temos construído nossos estudos e como eles, de um lado, colaboram para a história dos manuais pedagógicos e, de outro, podem ser confrontados com outras pesquisas e perspectivas de análise.

\section{SABERES EM VIAGEM: DA CONSTITUIÇÃO DOS ESTUDOS SOBRE MANUAIS}

Um ponto de partida possível para pensar a história da história dos manuais pedagógicos é atentar para a proximidade entre estes livros e outros manuais escolares. Dado que o estudo dos manuais dirigidos aos alunos dos mais diversos níveis de ensino - notadamente o primário e o secundário - é um campo de pesquisa incomparavelmente mais desenvolvido, será útil iniciar 
pelo reconhecimento de características comuns aos impressos escolares. Assim, os manuais pedagógicos começam a ser consideradosr parte das leituras promovidas pela escola, pois também são destinados aos alunos, sendo que o seu diferencial é justamente a finalidade da aprendizagem, pois nesse caso os estudantes e futuros professores são socializados para socializar crianças. Considerando as afinidades e especificidades existentes entre os manuais escritos para as crianças e os que são feitos para os futuros professores, podemos reter dois aspectos:

I. Ambos sustentam o processo de socialização escolar, organizam o discurso que institui os atores e sua subjetividade. No entanto, no caso dos manuais para professores, existe a construção de um discurso com foros de cientificidade acerca da natureza do ato escolar, do espaço-tempo da escola, da natureza infantil, da sua psicologia e do seu desenvolvimento, das questões filosóficas etc. que supostamente sustentam e legitimam o modo pelo qual os saberes são selecionados e a respectiva transmissão/apropriação é organizada. A socialização profissional do professor na sua formação produz efeitos sobre a socialização escolar das crianças, mas é acompanhada de um metadiscurso que visa a demonstrar a sua inevitabilidade e superioridade.

2. A formação de professores é palco de lutas intensas pela afirmação social e institucional de novos campos e disciplinas científicas (Nóvoa, 1987). O estudo da criança, a afirmação da pedagogia e da psicologia experimentais nos finais do século XIX e nas primeiras décadas do século $X X$ ilustram isso. $\mathrm{Ou}$ seja, se é verdade que os manuais pedagógicos podem ser considerados produtos da cultura escolar, eles também podem ser encarados do ponto de vista da constituição (sempre hipotecada de algum modo...) de um corpo de saberes profissionais docentes que sustentaria a possibilidade da existência sociológica da profissão de professor e, ao mesmo tempo, da existência de saberes científicos (dos especialistas das Ciências da Educação, que é a tal hipoteca...). Reprodução, circulação e apropriação desses saberes estão assim relacionadas também com as vicissitudes da institucionalização da formação de professores, da constituição de campos acadêmicos que a ela dizem respeito.

Os manuais pedagógicos foram escritos a fim de desenvolver tópicos relativos aos planos de estudos de escolas normais, institutos de educação e, em alguns casos, até de faculdades de filosofia, a partir de currículos e progra- 
mas oficialmente determinados e, na maioria dos casos, atingindo um número significativo de edições. Trata-se de certa trivialidade, familiaridade e ampla difusão que determinou um desinteresse por parte dos pesquisadores no que toca à sua produção e circulação.

Considerações semelhantes são feitas por Chopin (2000) em sua análise a respeito dos manuais para alunos da escola primária, sugerindo que, nesse aspecto, os manuais pedagógicos aproximam-se dos livros escritos para as crianças. Segundo este autor francês - um dos primeiros estudiosos que se dedicou ao exame dos manuais escolares até aproximadamente meados do século $X X$-, há poucas investigações sobre o material e faltou um esforço mais sistemático para sua conservação e catalogação. A quantidade de pesquisas dessa natureza aumentou a partir da década de 1960, um período de democratização do sistema educativo, de descolonização e aumento dos progressos técnicos. Os trabalhos então desenvolvidos privilegiaram questões a respeito da vida escolar, da constituição da memória coletiva (o nacionalismo, o patriotismo, a moral), ou mesmo do racismo. Assim, o exame do conteúdo dos livros versou sobre uma multiplicidade de temas, permitindo conhecer referências familiares a respeito de gênero, culturas, direitos humanos. Nos últimos 20 anos, houve uma mudança nesse tipo de interesse, decorrente não tanto da ampliação e diversificação da temática, mas, sobretudo, do desenvolvimento de projetos com novas perspectivas ou especializados em disciplinas e áreas nunca trabalhadas até então. Dos anos 1980 em diante, procurou-se construir uma história da literatura escolar, com a elaboração de inventários de coleções, identificação das leis que regularam o gênero, reconstituição da vida das editoras, da atuação profissional dos autores, da difusão e recepção do material etc., o que é favorecido pela ampliação das técnicas de armazenamento de dados. Em outro texto, também relativo à produção de estudos sobre manuais, Chopin (2002) assinala como uma das tendências atuais o interesse pela dimensão transnacional e pelo conhecimento da circulação das idéias e dos mecanismos de elaboração das identidades culturais em diferentes países.

Andrés (2002), ao introduzir o volume da revista Paedagogica Historica dedicado ao tema "Livros e educação: 500 anos de leitura e aprendizagem", oferece um panorama dos projetos de pesquisa concluídos nos últimos 20 anos e evidencia o significado que os livros escolares têm tido para os historiadores da educação ao longo do tempo. Um dos aspectos mais relevantes observados pela autora é a multiplicidade de palavras (livros-texto, manuais e livros 
escolares) usadas nas pesquisas para se referir à mesma categoria, a dos textos escritos para a educação formal, transmitindo conhecimentos e inserindo os jovens na vida cultural da escola. Essa variedade de termos nos conduz a afirmar a necessidade de se construir um "consenso acadêmico" sobre a denominação e categorização desse objeto, embora não haja dúvidas quanto à importância dos livros como elementos centrais na história do currículo e como fontes fundamentais para entender o funcionamento das disciplinas e das práticas escolares, das quais podem ser vistos como "símbolo" e "emblema".

Os textos escolares representam também fontes para conhecer a economia das publicações editoriais, incluindo-se aí as modalidades de impressão ou a semiologia da imagem. Nesse sentido, os educadores reconhecem que os impressos utilizados por alunos e professores permitem conhecer o cotidiano das salas de aula. Isso porque esta bibliografia organiza os conteúdos "legítimos" a serem transmitidos (Apple, 1995). No entender de Forquin (1993), a elaboração desse conjunto supõe uma seleção do patrimônio humano construído ao longo de gerações e ainda uma reelaboração dos tópicos escoIhidos em nome de propósitos didáticos. Tal imperativo obriga a emergência de modos de pensamento tipicamente escolares, constituindo uma espécie de cultura própria. Segundo Chopin (2000), os manuais são objetos complexos que devem disponibilizar aos estudantes saberes, valores morais, religiosos e políticos. Para o corpo docente, esse material auxilia o ensino, destacando algumas informações e sugerindo a adoção de determinados métodos e técnicas para sua transmissão.

Além dessa multiplicidade de aspectos, o autor ainda assinala outras razões para explicar a riqueza dos manuais escolares como fonte e como objeto de estudo. Uma delas refere-se ao fato de que esse gênero é produzido a partir de prescrições dos programas oficiais e, portanto, orienta de forma mais detaIhada do que tais instruções, o ensino que efetivamente ocorre durante as aulas. Tal repertório, no intuito de tornar seus escritos acessíveis ao leitor, constitui um corpus relativamente homogêneo, o que permite construir métodos comparativos de análise. É possível ainda empreender estudos seriais, acompanhando ao longo do tempo a aparição e o desenvolvimento de uma noção científica, de um método pedagógico em vários títulos, por exemplo, ou, ainda, as variações tipográficas apresentadas por eles. Trata-se da constituição de um campo de conhecimento recente, mas que tem despertado o interesse de muitos pesquisadores. O número 19 de Historia de la Educación (2000) reser- 
vou uma seção para trabalhos relativos a manuais escolares, publicando um balanço sobre as pesquisas na área desde a década de 1960 (Alain Chopin). Dele constam ainda: a apresentação da origem e evolução do Projeto Manes (Alejandro Tiana Ferrer e Gabriela Ossenbach Sauter), um trabalho a respeito do movimento editorial na Espanha (Miguel Beas Miranda) e uma série de artigos sobre publicações destinadas ao ensino de disciplinas específicas, tais como História (Verena Radkau García), História da Educação (Antonio Molero Pintado), Física (Antonio Moreno González) Gramática (Isabel Martinez Navarro). Como observa Benítez ao comentar o volume, estes textos ressaltam aspectos ainda pouco conhecidos sobre a literatura escolar.

Em seminário realizado na Faculdade de Educação da USP, Correia (2000) atenta para a riqueza dos manuais e chama a atenção para considerá-los peça essencial para entender como os intervenientes se representam ou são levados a representar-se a si mesmos, as relações que estabelecem uns com os outros, bem como com os saberes, o ensino e a aprendizagem escolares. Nesse sentido, o autor não nega a importância do exame dos planos de estudos, das disciplinas, programas e conteúdos, já que eles prescrevem o que se deve transmitir aos alunos. Mas é preciso atentar também para os livros que desenvolvem os tópicos dos currículos, que lhes estabelecem os sentidos legítimos mediante as seleções e interpretações apresentadas. A abordagem dos textos permite reconstituir os recursos discursivos com os quais os atores sociais da educação constroem suas práticas, representações e identidades.

De fato, os manuais para professores, e também os dos alunos, permitem múltiplas possibilidades de investigação, mobilizando diversos domínios do conhecimento: história, pedagogia, sociologia, lingüística, política, economia. Dentre vários estudos históricos sobre esse material, é possível assinalar uma publicação dirigida por Benito (1998), sobre o livro escolar na Espanha do pósguerra à reforma educativa. Um dos artigos incluídos nesta coletânea é assinado por Narciso de Gabriel Fernández e José Luis Iglesias Salvado, versando sobre livros e guias para o professor. Os autores desenvolvem uma investigação a respeito de obras feitas para orientar os professores no exercício do magistério e chamam a atenção para o fato de que o repertório serve tanto para estudantes - pois disponibiliza orientações para a aprendizagem - quanto para professores, sugerindo conteúdos e procedimentos de ensino. Nessa perspectiva, trata-se de textos centrais nas atividades escolares, cujas características e usos variam segundo o período, o contexto, a idade dos alunos, a matéria ou as exigências 
de cada método utilizado. Os autores optaram por centrar a atenção somente nos impressos dirigidos aos mestres já atuantes, tais como livros ou guias a respeito de questões morais, administrativas ou metodológicas.

Ainda no que se refere a produções espanholas, Pintado (2000) escreveu um artigo que discorre sobre a introdução da disciplina História da Educação nos currículos de cursos de formação docente e examina a bibliografia nacional e estrangeira que sintetizou os tópicos da matéria e circulou em seu país. Villela (2002) desenvolve esforço semelhante em tese que analisa a formação realizada nas escolas normais da Província do Rio de Janeiro durante o século XIX, tomando como uma das fontes um manual escrito para os normalistas, além de outras, como relatórios oficiais, reformas, programas das disciplinas e material pedagógico. Na França, há o trabalho de Roullet (1998) em que são analisados as propostas educacionais e os temas constantes nos títulos, compondo uma tipologia dos discursos veiculados. Tais estudos deixam entrever o fato já assinalado, que os manuais pedagógicos partilham características comuns a outros textos, também destinados ao uso de estudantes, mas apresentam especificidades importantes nos propósitos com os quais são escritos e nos modos pelos quais são produzidos.

A partir dessa retomada dos trabalhos, pode-se identificar o crescente interesse de pesquisadores sobre os manuais escolares e uma certa predominância dos estudos referentes aos livros destinados ao nível primário de ensino, se bem que seja notável o progressivo aumento de análises de textos destinados à formação profissional dos professores.

\section{TEMPOS, TEMAS E FONTES DAS PESQUISAS}

Em nossa reflexão acerca da história da história dos manuais escolares, especialmente da história dos manuais para professores, há que se assinalar primeiramente na bibliografia examinada uma certa variedade de interesses de estudo e, conforme já observaram Ossenbach e Somoza (200I), uma certa "ambigüidade terminológica" para denominar o objeto de pesquisa em pauta. Este pode ser referido nos trabalhos de diversas formas: livros escolares, livros de texto, livros para crianças, manuais, almanaques, cartilhas, livros de cópias, catecismos, obras de autores determinados, como Walter Benjamin, Comenius, Rousseau e Mary Somerville e até livros infantis. Os trabalhos referem-se a 
diversos lugares (EUA, Brasil, Argentina, Austrália, México, Polônia, Lituânia, Espanha, França, Portugal, Inglaterra), mostrando uma variedade significativa de períodos cronológicos. Entre os períodos mais recuados estão os séculos $X V$ e XVI, com uma concentração de pesquisas nos séculos XIX e XX.

Quando se atenta para as investigações acerca dos manuais para professores, observa-se a pouca visibilidade daquilo que difere essa categoria de outros impressos usados pelos alunos (observações semelhantes são feitas por Ossenbach e Somoza, 200I). As fontes, tempos, lugares e temas de pesquisas, tal como aparecem nos trabalhos sobre manuais usados por alunos e pelo corpo docente, de certa forma, não se diferenciam de modo significativo. De fato, é de se esperar que as fontes sejam semelhantes tanto quando são estudados os manuais para alunos quanto os manuais para professores. Trata-se, geralmente, de depoimentos, manuscritos, revistas especializadas e, evidentemente, dos próprios manuais. Entretanto, no que tange aos temas investigados, é notável que os interesses, tanto num como noutro caso, sejam múltiplos, o que pode estar relacionado com as especificidades de cada livro, porque, conforme salientamos anteriormente, o que muda é a finalidade do ensino: no caso dos normalistas, trata-se de socializar os alunos para socializar as crianças. Mas há que se reconhecer algumas peculiaridades nos tempos estudados em cada caso, uma vez que as investigações relativas aos manuais para professores versam predominantemente sobre momentos anteriores àqueles estudados em trabalhos sobre livros para crianças, quando os sistemas de ensino começam a constituir e consolidar a preocupação com regulações acerca do ingresso na carreira do magistério (por meio dos concursos) e da formação inicial da categoria (em cursos especializados). Assim, uma boa parte dos trabalhos sobre manuais para professores toma, como marco temporal, meados do século XIX e início do século XX. No caso dos manuais para alunos, os períodos mais abordados referem-se a meados e ao final do século $X X$. Não obstante, concordamos com Ossenbach e Somoza (200I) quanto à ausência de uma diferenciação mais clara dos manuais para professores em relação aos manuais para alunos, o que as pesquisas acabam deixando de lado porque não assinalam as peculiaridades sobretudo dos usos aos quais cada livro se destina.

Além de uma conceituação mais rigorosa, a construção de uma história dos manuais tem como uma das alternativas férteis a capacidade de transformar esses livros de objetos de uso comum no cotidiano escolar, tal como se apresentam, em objetos de pesquisa, construídos teórica e metodologicamente 
para romper com as evidências do senso comum, como sugere Bourdieu ( 1980$)$. Assim, para além de descrever a apresentação dos manuais, uma perspectiva como essa envolve uma problematização e uma conceituação das relações desses livros com outras dimensões da escola. $\bigcirc$ conjunto dos trabaIhos já desenvolvidos na área evidencia o potencial dos manuais como uma fonte que dá a ver aspectos importantes da vida escolar, notadamente as fases de uma determinada disciplina do currículo tal como explicadas em alguns manuais destinados a esse fim, ou a identificação da carreira de um autor e das razões que o levaram a escrever um manual. É possível também examinar o conteúdo de um título lembrado pelo grande número de edições ou a localização de iniciativas editoriais no setor.

A partir de tais questões seria possível operar uma espécie de "reinterpretação criativa" (Bourdieu, 1996) das teorias acerca dos manuais para professores. Ressaltamos a necessidade de dedicar suficiente cuidado à análise do lugar e do papel desses livros no quadro da cultura escolar, de modo a colocar em evidência a capacidade desses livros para produzir um capital específico do corpo docente, o dos saberes que orientam e dão legitimidade à prática desses profissionais, podendo assim ultrapassar a sua função de suportes e portadores dos conteúdos selecionados para esse fim. Conforme assinala Bourdieu, a fertilidade de um investimento como esse

...é fazer funcionar a propósito de um objeto diferente (os manuais para professores, no caso) o modo de pensamento que aí se exprime, reativá-lo em um novo ato de produção, tão inventivo e original quanto o ato inicial (este último tomado aqui como o conjunto mais amplo das pesquisas sobre manuais escolares em geral). (1996, p.206-207)

É justamente na busca de compreender o modo de pensamento dos manuais para professores que procuramos inserir essa bibliografia no quadro de uma cultura profissional docente, analisando as lógicas de apropriação por meio das quais os saberes do magistério são construídos e dados a ler. Convém esclarecer que o conceito de apropriação aparece aqui tal como o entende Chartier (1990), referindo-se à liberdade ao mesmo tempo criadora e regulada dos leitores, bem como às múltiplas interpretações às quais um pensamento é suscetível. Essas hipóteses conduzem a indagar sobre os usos que os escritores dos manuais fizeram do que leram, buscando apreender as práticas de síntese e divulgação da literatura por eles mencionada. 
Cumpre, então, destacar a problemática que tem conduzido nossos exames, a saber, a constituição dos manuais como "leituras de leituras", ao mesmo tempo produto do contato de lectores com obras originais de auctores citadas nos manuais, já que estes livros dão a ler aquilo que se considera ser o que há de melhor na literatura educacional. Os dois termos - auctorese lectores - são utilizados no sentido sugerido por Bourdieu (1990) em texto intitulado "Leitura, leitores, letrados, literatura". Nesse artigo, o autor chama a atenção para a diferença entre o lector, aquele que segundo a tradição medieval interpreta um discurso anterior, e o auctor, responsável pela elaboração de uma obra original. De modo geral, os manuais pedagógicos apresentam-se no intuito de viabilizar o acesso dos normalistas e, evidentemente, de pessoas que estão sendo iniciadas na área pedagógica, ao conteúdo da bibliografia reconhecida entre os educadores. Nesse sentido, são comuns nos títulos e prefácios os termos "compêndio", "introdução", "texto básico", "coletânea" e a própria palavra que aqui foi usada várias vezes: "manual”. Ao mesmo tempo, tais livros são entendidos como produtores de um discurso que será apropriado por outro grupo de lectores, a saber, os alunos normalistas aos quais se dirigem para intermediar o contato deste público com as idéias dos auctores referidas de maneira sumária e compreensível, divulgando-as a leitores ainda não especializados na área. É essa dupla natureza de produto e produtor de um discurso pedagógico que permite aos manuais para professores ocuparem um lugar especial na cultura escolar e pedagógica!.

$\mathrm{Na}$ medida em que o objeto em pauta constitui-se pela referência a autores selecionados de diversos campos, entre pedagogos, psicólogos, médicos, biólogos, filósofos, historiadores, políticos etc., os manuais pedagógicos devem ser pensados no conjunto das relações objetivas (Bourdieu, 1996) entre os campos da Pedagogia, Psicologia, Medicina, Biologia, Filosofia, História, Política etc., pois são estas relações que dão sentido aos saberes ensinados nos manuais. Tais articulações não podem - ou pelo menos essa não seria uma pers-

I A essa altura, cabe sublinhar que no estudo dos manuais aqui apresentados consideraram-se somente os títulos relativos a questões diretamente relacionadas ao ensino, daí a seleção de livros sobre Pedagogia, Didática, Metodologia e Prática de Ensino - disciplinas destinadas a este fim. Para marcar tal especificidade é que optamos por nomear o nosso corpus de estudo como manuais pedagógicos. Outras questões são trazidas por manuais que também se destinam aos professores, mas que se referem a outros campos de conhecimento, como é o caso da Psicologia, Biologia e Sociologia Educacionais entre outros, exigindo outras investigações. 
pectiva fértil - ser pensadas em nível nacional apenas, mas sim em um contexto internacional, pois as referências mobilizadas nos manuais não se restringem a produções do seu país de origem. Por exemplo, as citações a John Dewey não são comuns, evidentemente, apenas nos EUA; também aparecem em outros lugares. No Brasil, esse é o autor quantitativamente mais referido num período significativo, de 1930 a 1971, até quando foi possível investigar. Mas essas apropriações revestem-se segundo épocas e tradições; Dewey e outros auctores foram reconhecidos e lidos nos manuais de vários modos².

Essa leitura parece aproximar-se da imagem de um circuito, no qual as idéias originais de um autor transformam-se pelas interpretações de lectores (no caso, quem escreve os manuais) que as dão a ler a outros lectores, os quais podem compor um público variado, desde os próprios normalistas até escritores de outros livros, inclusive de outros manuais pedagógicos, que vão continuar o processo de divulgação e apropriação da obra de um auctor, processo este que assume particularidades em dada configuração histórica e geográfica considerada. Tome-se como outro exemplo a divulgação das idéias de Luzuriaga, que, entre os portugueses, foi lido via Theobaldo Miranda Santos, um lector brasileiro responsável pela escrita de uma série de manuais para professores (publicados numa coleção organizada pela Companhia Editora Nacional) que chegaram a circular em Portugal (Correia, Silva, 2002). Assim, como "leituras de leituras", os manuais participam desse circuito como resultado da seleção e síntese de saberes e como um espaço de produção de conhecimentos, conforme procuramos explicitar. Há que se ter em conta, portanto, "as interações, entre os autores e os críticos ou entre os autores e os editores, (...) as relações objetivas entre as posições relativas que uns e outros ocupam no campo, ou seja, a estrutura que determina a forma das interações" (Bourdieu, 1996, p.208). São essas as linhas gerais que orientam nossa pesquisa sobre manuais pedagógicos.

\section{SABERES EM VIAGEM NOS MANUAIS PEDAGÓGICOS}

A identificação do universo de referências dos manuais pedagógicos, bem como as articulações desses livros com os programas oficialmente definidos para

2 Um estudo mais detalhado das apropriações de Dewey no Brasil pode ser encontrado em Silva (2001, p. 133-159). 
os cursos de formação de professores primários em Portugal e no Brasil, entre 1930 e 1970, representam um ensaio, entre vários em curso (ver, especialmente, o artigo de Carvalho e Cordeiro, 2002), no delineamento de objetos de pesquisa e de metodologias de trabalho que, se deseja, possam contribuir para uma renovação na abordagem comparada em História da Educação em língua portuguesa. Tentativa modesta e incipiente, especialmente em termos de resultados, é forçoso reconhecer. Convém sublinhar, no entanto, os aspectos positivos e promissores quanto ao futuro dos esforços já desenvolvidos. $\bigcirc$ processo de escolha do tema, de definição do âmbito cronológico e do estabelecimento de uma metodologia de pesquisa comum colocou em evidência a importância, para projetos de parceria e abordagem comparada, de um percurso prévio de explicitação e desconstrução mútua dos quadros teóricoconceituais e metodológicos de referência com os quais cada um de nós tem trabalhado em Portugal e no Brasil (neste caso, em São Paulo).

A mudança de escala de construção do objeto de pesquisa e do olhar que o interroga suscitam um sem número de reflexões e de problemas a resolver em comum, que ajudam a reequacionar questões tradicionais e a procurar novas pistas e hipóteses de explicação. A fabricação do discurso pedagógico vista através dos manuais pedagógicos para professores sugere diferentes tipos de circulação e apropriação da literatura pedagógica no quadro das redes sociais da escolaridade constituídas intra e internacionalmente. A tomada, como ponto de partida, do quadro nacional de cada um dos países significa começar com os materiais empíricos e as metodologias convencionais para, gradualmente, ensaiar aproximações com outros quadros de referência. É verdade que algumas questões ficam por responder ou não estão resolvidas de modo convincente.

Os elementos aqui reunidos acerca dos manuais pedagógicos como instrumentos de formação dos professores primários e como veículos do discurso pedagógico e de mobilização de referências internacionais demonstram, contudo, tanto a necessidade como a possibilidade imperativas de orientar a pesquisa na perspectiva apresentada. É verdade que, se nos limitamos a constatar a primazia da menção a Dewey e a Aguayo, no caso brasileiro, ou a Claparède e Decroly, em Portugal, isso, por si só, será pouco elucidativo quanto ao processo de constituição dos discursos sobre a formação profissional dos professores e a pedagogia nos dois países.

A mobilização de referências a autores, obras, países e instituições re- 
veste-se de uma complexidade muito maior do que as seriações quantitativas. Estas pouco revelam em termos imediatos e diretos, uma vez que são úteis para suscitar interrogações acerca das razões que sustentam a respectiva ocorrência. À volta das figuras emblemáticas, cuja proeminência se altera, existe um sem número de autores e obras, de traduções e adaptações, de sínteses que geram uma constelação de referências, de geometria e proveniência variáveis. Quando falamos de proveniência referimo-nos a autores e a terminologias que pertencem a arquiteturas conceituais inseridas em diferentes tradições culturais, científicas e lingüísticas. Os manuais pedagógicos são bom exemplo de uma corda discursiva cujos fios ainda agora começamos a entrever e que podem ajudar a ver os percursos da escolaridade de outros modos. Se os livros em pauta determinam um modelo de profissionalização docente, como aqui temos defendido, interessa encontrar aproximações e distâncias entre pensamentos e práticas por meio deles. Em outras palavras, interessa saber como os saberes "viajam" nas citações, referências e usos internacionalmente feitos de autores, obras e experiências que, ao serem apropriados, constroem os sentidos do ofício de ensinar.

\section{REFERÊNCIAS BIBLIOGRÁFICAS}

ANDRÉS, M. Introduction. Paedagogica Historica: International Journal of the History of Education, Belgium, Universitaire Stichting van België, v.37, n. I, p.9-17, feb. 2002.

APPLE, M. W. Trabalho docente e textos: economia política das relações de classe e de gênero em educação. Porto Alegre: Artes Médicas, 1995.

BENITEZ, M. de P. Los Manuales escolares: um nuevo campo de conocimiento. Historia de la Educación: Revista Interuniversitaria, Universidad de Salamanca, n. 19, p.5-I I, 2000.

BENITO, A. E. (org.). Historia ilustrada del libro escolar en España de la posguerra a la reforma educativa. Madrid: Fundación Germán Sánchez Ruipérez, 1998.

BOURDIEU, P. Coisas ditas. São Paulo: Brasiliense, 1990. Leitura, leitores, letrados, literatura, p. $134-148$.

A Economia das trocas lingüísticas. o que falar quer dizer. São Paulo: Edusp,

1996. A Força da representação, p. 107-1 16. Le Métier de sociologue. Lahagu: EHESS, 1980. 
As Regras da arte. São Paulo: Cia. das Letras, 1996a.

CARVALHO, L. M.; CORDEIRO, J. Brasil-Portugal nos circuitos do discurso pedagógico especializado: 1920-1935. Lisboa: Educa, 2002. (Série Cadernos Prestige)

CHARTIER, R. A História cultural: entre práticas e representações. Lisboa; Rio de Janeiro: Difel; Bertrand Brasil, 1990.

. O mundo como representação. Estudos Avançados, v.5, n. I I, p. 173 - 191 ,

|99|.

CHOPIN, A. L'Histoire du livre et de l'édition scolaires: vers un état des lieux. Paedagogica Historica: International Journal of the History of Education, Belgium, Universitaire Stichting van België, v.37, n. I, p.21-50, feb. 2002.

Los Manuales escolares de ayer a hoy: el ejamplo de Francia. Historia de la Educación: Revista Interuniversitaria, Universidade de Salamanca, n. 19, p. I3-36, jun. 2000.

CORREIA, A. C. Olhar a escola através dos livros de texto para formação de professores. São Paulo, 2000. mimeo. [Apres. no Seminário de Estudos, São Paulo, Feusp, 2000]

CORREIA, A. C.; PERES, E. T. Learning to be a teacher by the book. professional images, school curriculum and models of children's learning in textbooks for elementary schoolteachers pre-service training in Portugal (1870-1950). Madrid, 2000. mimeo. [Apres. Ische 22, Alcalá de Henares-Madrid].

CORREIA, A. C.; SILVA, V. B. Manuais pedagógicos: Portugal e Brasil 1930 a 197I: produção e circulação internacional de saberes pedagógicos. Lisboa: Educa, 2002. (Série Cadernos Prestige)

FERRER, A. T. El Proyeto Manes y la investigación histórica sobre los manuales escolares: siglos XIX y XX. Historia de la Educación: Revista Interuniversitaria, Universidad de Salamanca, n.19, p.179-194, 2000.

FERNÁNDEZ, N. G.; SALVADO, J. L. I. Los libros y guias para el maestro. In: BENITO, A. E. (dir.) História ilustrada del libro escolar en España de la posguerra a la reforma educativa. Madrid: Fundación Germán Sánchez Ruipérez, 1998. p.439-468.

FORQUIN, J. Escola e cultura. Porto Alegre: Artes Médicas, 1993.

GARCÍA, V. R. ¿Uma Lucha contra los molinos? El Instituto Georg Eckert y los manuales escolares. Historia de la Educación: Revista Interuniversitaria, Universidad de Salamanca, n. 19, p.39-49, 2000. 
GONZÁLEZ, A. M. La Física en los manuales escolares: un medio resistente a la renovación ( 845 - 1900). Historia de la Educación: Revista Interuniversitaria, Universidad de Salamanca, n. 19, p.51-93, 2000.

HISTORIA de la Educación: Revista Interuniversitaria, Universidade de Salamanca, n. I 9 , jun. 2000.

MIRANDA, M. B. La Asociación Nacional de Editores de Libros de Texto: desde la transición hasta el siglo XXI. Historia de la Educación: Revista Interuniversitaria, Universidad de Salamanca, n. 19, p. I 41-178, 2000. [Entrevista a Don Mauricio Santos]

NAVARRO, I. M. La Gramática en los manuales escolares de Bachillerato. Historia de la Educación: Revista Interuniversitaria, Universidad de Salamanca, n. 19, p.95-119, 2000.

NÓVOA, A. História da educação: percursos de uma disciplina. Análise psicológica, Lisboa, n.4, p.417-434, 1996.

Le Temp des professeurs. Lisboa: Inic, 1987.

NÓVOA, A.; SCHRIEWER, J. (org.). A Difusão mundial da escola. Lisboa: Educa, 2000.

OSSENBACH, G.; SOMOZA, M. Los Manuales escolares como fuente para la historia de la educación en America Latina. Madrid: Universidad Nacional de Educación a Distancia, 2001.

PAEDAGOGICA, Historica: International Journal of the History of Education. Belgium, Universitaire Stichting van België, v.37, n. I, feb. 2002.

PINTADO, A. M. Los Manuales de historia de la educación y la formación de los maestros: 1900-1930. Historia de la Educación: Revista Interuniversitaria, Universidad de Salamanca, n.19, p.121-139, 2000.

ROULLET, M. L'Avenement d'une "science pedagoguique": manuels de pédagogie et de psychologie dês écoles normales en France entre 1880 et 1920. Genève, 1998. These (Doct.) Université de Genève.

Les Manuels de pédagogie (/880-1920): apprendre à enseigner dans les livres? Paris: PUF, 200I.

SARMIENTO: Anuário Galego de Historia da Educación. Espanha, Universidade de Coruña, n. I, 1997.

SAUTER, G. O. La Investigación sobre los manuales escolares en América Latina: la contribuición del Proyeto Manes. Historia de la Educación: Revista Interuniversitaria, Universidad de Salamanca, n. 19, p. 195-203, 2000. 
SILVA, V. B. História de leituras para professores: um estudo da produção e circulação de saberes especializados nos "manuais pedagógicos" brasileiros ( 930 - | 97| ). São Paulo, 2001 . Dissert. (Mest.) Feusp.

VILLELA, H. O. Da palmatória à lanterna mágica: a escola normal da Província do Rio de Janeiro entre o artesanato e a formação profissional (| 868- | 876). São Paulo, 2002. Tese (Dout.) Universidade de São Paulo.

Recebido em: janeiro 2004

Aprovado para publicação em: agosto 2004 